\title{
Jonathan Shepherd: 'People are entitled to their own opinions but not their own facts'
}

Interview by Ruth Doherty

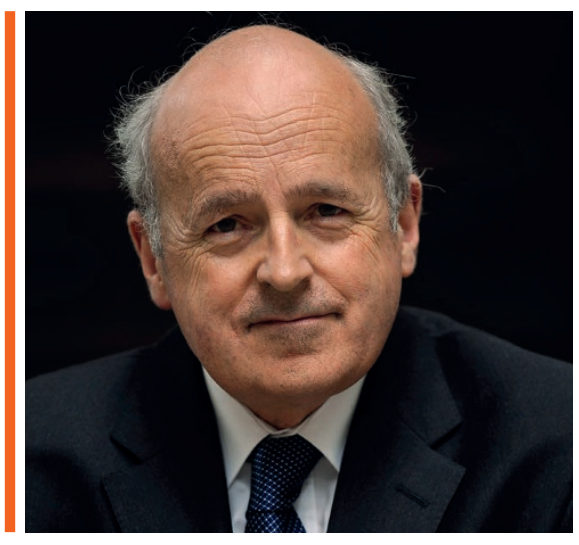

How did someone who works as a maxfac surgeon end up reducing crime?

It all started when I was training to be a consultant in Leeds in the 1980s. I remember in the middle of an operating list in Wakefield somebody pointing out that we would always see higher numbers of assault patients during a miners' strike. I also observed that most of our assault patients had been injured in a few particular pubs and only a small number in all the other pubs. So when I went to Bristol as a senior lecturer in 1983 I decided to investigate assault as the topic of my $\mathrm{PhD}$ research. My supervisors were Crispian Scully and the professor of social work, Phyllida Parsloe.

The crossover from dentistry and medicine into criminology was so novel that I discovered a huge amount. People had previously carried out straightforward audits of the causes of facial and dental injury but they weren't really proper investigations, just counts of incidents.

The really unexpected discovery which has driven much of my subsequent research and policy work was the finding that most of the violence that puts people in hospital was not known to the police. Indeed, through regularly matching assault patient data in Bristol with assaults reported to the police over identical time periods I discovered that three quarters of the incidents that put people in $\mathrm{A} \& \mathrm{E}$, on my operating table and in our hospital clinics

Jonathan Shepherd is Emeritus Professor of Oral and Maxillofacial Surgery at Cardiff University. In addition to his considerable clinical work as a consultant, through his research Jonathan has been active in the field of criminology and its overlap with health. His research in this area has led to significant reductions in violence, initially in South Wales where he carried out the work but since then across the UK and in cities around the world. Jonathan pioneered the establishment of professional colleges for the police, probation and school teachers. Recently, he spearheaded a Declaration on Evidence, which was signed in November 2017 by leaders of all the Royal Colleges, the College of Policing and the Chartered College of Teaching and commits them to put evidence at the heart of their work.

were not known to the police. I thought this was shocking. The law department at Bristol University didn't know why it was either! So, together, we were awarded a research grant to find out. It turned out that the reason the police didn't know about all this violence was because their knowledge depended on people reporting it to them - but many people don't report assault. Often, people injured in assault fear reprisals if they report, don't want their own conduct scrutinised too much, or think: 'what can the police do anyway?' That discovery, which has since been replicated in a number of other countries in Europe and in the US, has been the real prompt to keep going. I realised this was new and wanted to see what else could I find that was new.

\section{What did you discover next?}

I studied the levels of anxiety and depression experienced by people with facial injuries caused by accidents and those with the same injuries caused by assault. We found that the levels of anxiety and depression of those injured in violence remained high whereas those with comparable injuries caused by accidents became less anxious and/or depressed in the recovery phase.

Another finding was that $10 \%$ of assault patients (in an audit carried out in Bristol) had been injured with glass weapons. We then did a national study in five A\&Es across England over a bank holiday weekend in the late 1980 s which showed that the glass weapons mostly used to inflict injury were straight-sided beer glasses, called 'nonicks'. After that, the materials lab at Bristol Dental School resounded with the sounds of glass breaking as we tested the impact resistance of different glasses of this type. We found that we couldn't break one type of the glasses in our (impactometer) machine and that this was because it was made of toughened glass. By then I was in Cardiff and there we did a randomised trial of toughened glasses in pubs in the West Midlands and South Wales. It was clear that the tougher glasses were associated with significantly fewer injuries.

After that, I thought, there's no point in just publishing this, we need to make sure the glasses used in pubs change. So I contacted the Welsh Development Agency and we put together 'The Face of Wales Campaign' to convince the trade to switch to toughened glass.

Other than the change to toughened glass, how exactly do health data help to reduce assault levels?

In 1997 I convened the first meeting of what became the Cardiff Violence Prevention Board. The aim was to pull together data from both the police and $A \& E$ to get a more complete picture of what was 
1 happening. Making this combined data available to the police and the city council made it possible for them to identify and then target areas where violence occurred more successfully. The Board continues to be made up of police, local government, A\&E clinicians and volunteer street pastors and through this we developed the 'Cardiff Model.'

There are three stages to reducing violence using the 'Cardiff Model':

- Firstly, you have to collect key information in $\mathrm{A} \& \mathrm{E}$ and this must be sustainable.

- Secondly, you have to combine and analyse police and A\&E data together.

- Thirdly, and really importantly, violence prevention boards are needed to translate the data into practical prevention in cities.
2017 there were 122,286 fewer violence-related A\&E attendances compared to 2010 . So people should not think that we are becoming more violent - society is becoming less violent. It's a great example of fake news that the media are delighted to scrutinise police data on violence to look for evidence of numbers going up and interpret that as a crime wave. It's clear though, that homicides and knife violence are now increasing.

\section{Why was violence concentrated in particular pubs?}

The research we carried out subsequently showed that it was basically to do with safety within licensed premises and how they were regulated. Because clubs and pubs are closed environments, that is there are no police

\section{'Three quarters of the incidents that put people in $A \& E$, on my operating table or in our hospital clinics were not known to the police...'}

We trialled various ways of collecting the information in $\mathrm{A} \& \mathrm{E}$ and by far the best was to get receptionists involved. They are experts in recording information from patients. The data are completely anonymised and shared, which allows the police to identify hotspots that need a police presence where there wasn't one before. There was a bit of scepticism from the police to start with - they thought it couldn't be true that they are missing all those assaults. But when they saw their own reports matching up with what we were saying they realised our data from $A \& E$ were really useful and from then on they were completely up for using this as a new source of intelligence. Surgeons and the police often have a common outlook - we both do investigations and operations, and we are both action-oriented professionals, practical people.

\section{Has the 'Cardiff Model' for violence prevention worked?}

Almost as soon as we started sharing the data and using it for prevention, Cardiff started becoming safer whereas other cities in the UK saw violence remaining the same or increasing. That was 2003-2007. In 2008, the government picked this up in the National Alcohol Strategy and more and more towns and cities started to use our model. Violence has been going down consistently year on year according to the $A \& E$ data that we collect across the country. In officers inside, then unless there's really good scrutiny in local A\&Es, and regulation and high quality staff training there's potential for violence and anti-social behaviour.

Now that we have good health data coming both from $A \& E$ departments and the police there is nowhere for the bad landlord to hide. $\mathrm{He} /$ she will know that if they send someone to hospital with a cut face, broken jaw or smashed up teeth it will be recorded, this information anonymised and then shared with police and licensing authorities. Before we started using health data for violence prevention purposes, landlords thought they could pop people up to $\mathrm{A} \& \mathrm{E}$ and not expect any follow-up.

\section{So all the while you were researching you continued your clinical work?}

One of the great benefits of the clinical academic role in medicine and dentistry is that academics don't just practise but have time for research and teaching. Right at the beginning of my career as an academic, I decided the issues I wanted to address were the real-life problems faced by the patients coming into my clinic. That made me want to focus my effort on assault because, certainly in the 80 s and 90 s, it was an increasing problem and thousands more people were injured in this way year after year. It was causing huge pain and suffering, and costing taxpayers a fortune.
You've been central to an initiative which will promote the adoption of evidence by medics, teachers and the police. Tell us more about this.

While chairing the Cardiff Violence Prevention Board, I realised it was odd that medics and dentists have professional bodies which do so much to raise standards based on best evidence, eg the Royal Colleges and their dental Faculties, but that none of that infrastructure existed for the police, probation, teaching or for local government.

I believe that reliable evidence generated by academics across all sectors needs to be turned into professional guidance (eg by NICE in healthcare) so it can be adopted in practice. This won't happen by accident. So I thought: let's campaign for a College of Policing. I gained Home Office support for this idea and it was launched in 2013. In a similar vein the Probation Institute, now the professional body for probation officers, was launched in 2014 and the Chartered College of Teaching, the new professional body for school teachers, was founded in 2016.

I initiated and wrote a Declaration on Evidence and took that through the boards of the Academy of the Medical Royal Colleges, College Of Policing and Chartered College of Teaching. Leaders of all the Colleges, 27 institutions in all, signed this declaration at an event at the Royal Society in November 2017, kindly funded by Nesta and chaired by Lord Gus O'Donnell, the former cabinet secretary.

These bodies have declared that they expect all their members to take full account of the available evidence when they advise people - clients, patients, government. It's a step to increasing evidence-based practice.

\section{How do you ensure colleges maintain their standard advancing role?}

History shows that if professional bodies are not grounded in continually evolving best evidence they die. The trick is to keep close to the evidence and keep improving and adjusting the exams needed to become a member or fellow so that they reflect current evidencebased practice. All professionals worth the name will want to support this process.

\section{How much of policy making within healthcare is evidence-based?}

We all need to be aware that evidence is never going to be complete and clinical judgement is always going to be important. We need to remember that the guidance that 
NICE, and equivalent bodies in other sectors, produces is guidance, not the law. On the other hand it is irresponsible not to take full account of that evidence.

I think it's great when the media pick up on new findings but it's confusing sometimes. People read one month that $\mathrm{X}$ is better than $\mathrm{Y}$ but the next month different experts produce different conclusions. But that is the nature of evidence and we depend on journals, like the $B D J$ and $B M J$, to apply rigorous quality controls on what is published and what isn't.

\section{What can GDPs do to promote evidence-based practice within the bounds of the current contracts?}

Professionals by definition want to do the right thing and that's down to professional training. I think it's about engaging with the evidence about what works and that can happen in all sorts of different ways - by reading high quality journals, by taking the membership of your professional body seriously, and particularly by really scrutinising evidence and changing course if you feel that the evidence is convincing. It means recognising the value of good trials and knowing the difference between randomised trials and case reports and what each means and can teach us in our professional lives. The Faculty of General Dental Practitioners (UK) and its standard-setting role is hugely important and needs to be supported by GDPs.

\section{Have you faced resistance?}

Many times. An example of this was my team's research that showed that prophylactic removal of wisdom teeth was not the right strategy. Reflecting this finding, we wrote a $B M J$ editorial basically saying that prophylactic removal of third molars should be abandoned. This led to a significant reaction from consultant colleagues; the next week there were five letters in the journal disputing this conclusion. I got a letter from the president of the British Association of Oral and Maxillofacial Surgeons telling me I'd betrayed the specialty. A debate in the national press followed. NICE guidance in 2000, reiterated more recently, confirmed that routine prophylactic removal of third molars should be discontinued according to the available evidence. This remains current guidance. That doesn't mean that it will forever be set in stone. If reliable, valid evidence is produced that this strategy should change then policy should of course change.
Another example comes from our campaign for the change to toughened glass in pubs. I was sitting in my dental school office in Cardiff one evening when I got a call from a director of a glass company in the North of England to tell me that our research was going to put 250 employees on the dole queue. In the end, that company diversified into polycarbonate glassware and as far as I know did very well because they reacted quickly to the need for change. Reassuringly, Home Office statisticians estimated that there were around 40,000 fewer glass-related injuries in England and Wales in the year after the switch to toughened glass.

\section{How do you cope with such a phone call?} It's about sticking with the evidence. Changing practice on the basis of convincing new evidence means campaigning and that is hard work. It takes time and openness to good arguments that what is proposed might need to be amended. Letting go a practice which has been shown to be second rate often feels like bereavement, but we should all be prepared to change course. There are all sorts of initially startling reforms that we end up taking for granted, like not drinking and driving, wearing seatbelts and not smoking inside pubs.

People are entitled to their own opinions but not their own facts. And it's worth remembering that there can often be powerful vested interests to do the wrong thing. The way that oral surgeons and the dental profession more widely responded to the NICE guidance dad encouraged me to write to some of the embassies listed in it for more information and paid for the postage. Those embassies sent back maps of their railway and road systems which I loved and I ended up writing to all 58 embassies. I think that encouraged me to follow my nose for information as a teenager, which had an impact on my research later.

I also think it takes just one significant discovery to make you want to find the next one and that keeps you inspired. I remember one of the consultants I worked for when I was a house surgeon saying 'There's nothing new under the sun' but of course that's entirely wrong; there are all sorts of new things to discover. It's important to always look for the next step and to keep going no matter how unorthodox it might appear. I don't mean become eccentric and doing things that are implausible and silly, but following the data is key.

\section{You have, I believe, built a working blast furnace - why?}

That was great fun! I've always had an interest in industrial and railway history, and when we moved to South Wales, I was very excited as that is where Richard Trevithick put the very first powered vehicle on a railway line, in 1804. I became interested in the iron and steel industry and took our two teenage boys to look at the remains of long abandoned blast furnaces in the Welsh valleys. I realised this is a really simple process - all you have to do is

\section{'I decided that the issues I wanted to address in my research were the real-life problems faced by patients coming into my clinic.'}

regarding the prophylactic removal of wisdom teeth is a tribute to their professionalism. When the need for change emerged, numbers of removals fell off very rapidly, some three or four years before NICE published its guidance.

\section{You appear to have approached the problem of crime from a different angle to find effective solutions. Is there a trick to applying this type of thinking to identify problems?}

I grew up in a family who encouraged my interest in lots of different things, particularly my father - a GDP in Devon. For example, we had a Whitakers Almanack at home and through that I got interested in maps. My get a furnace up to a really high temperature (about $1,400^{\circ} \mathrm{C}$ ) with coke, iron ore and a little flux and you can smelt the ore.

My first prototype furnaces all melted - we had a problem. Then, one day I was walking across Green Park to a meeting at the Home Office and there was a guy in the park with leaf blower over his shoulder and I thought 'that's the answer to my blast problem. Llanwern Steelworks gave me the recipe, some bags of high temperature resistant concrete and a few bags of iron ore. We sourced some industrial grade coke and put the furnace together. We have some chunks of rather crude iron around our garden now. The furnace eventually cracked but it was fun while it lasted. 